\title{
Networking Digital Platforms and Healthcare Project Finance Bankability
}

\author{
Roberto Moro-Visconti
}

check for updates

Citation: Moro-Visconti, R.

Networking Digital Platforms and Healthcare Project Finance Bankability. Sustainability 2021, 13, 5061. https://doi.org/10.3390/ su13095061

Academic Editors: Cristina Coscia and Elena Fregonara

Received: 1 April 2021

Accepted: 27 April 2021

Published: 30 April 2021

Publisher's Note: MDPI stays neutral with regard to jurisdictional claims in published maps and institutional affiliations.

Copyright: (C) 2021 by the author. Licensee MDPI, Basel, Switzerland. This article is an open access article distributed under the terms and conditions of the Creative Commons Attribution (CC BY) license (https:// creativecommons.org/licenses/by/ $4.0 /)$.
Department of Economics and Business Management Sciences, Università Cattolica del Sacro Cuore, 20123 Milan, Italy; roberto.moro@unicatt.it

\begin{abstract}
Framework: Healthcare project finance (PF) involves long-term structural investments in hospitals, typically within a public-private partnership (PPP). Banks represent the third major stakeholder, supporting the private player. Within this well-known framework, digital platforms represent a new virtual stakeholder, operating as a bridging node that incorporates information, and eases transactions. The relationships among the stakeholders are re-engineered around the platform and may be expressed with network theory patterns, even considering its multilayer extensions. Justification: As these investments are highly leveraged, especially during the construction phase, bankability represents a major sustainability concern. Objective: The research question is focused on the savings deriving from the introduction of networked digital platforms, and on their impact on bankability, shaping a new PPP model. Methodology: The study is conducted through (a) an economic-financial sensitivity analysis where digital savings impact on key PF parameters, including bankability; (b) a mathematical interpretation, based on network theory, where the stakeholders of two ecosystems-respectively, without and with a digital platform-are compared. Results: The creation of a value-adding "pie" anticipates its partitioning among the value co-creating stakeholders. This study represents an advance in the field, showing how technological innovation may improve the overall bankability and the value creation of leveraged infrastructural investments, even beyond the healthcare industry.
\end{abstract}

Keywords: network theory; scalability; smart healthcare; public-private partnerships (PPP); Value for Money; economic sustainability

\section{Introduction}

The aging population, public budgetary pressures, worldwide demographic growth, and dated infrastructure weaken the capacity of most developing nations to deliver proper healthcare services. The healthcare industry is a major industrial sector in numerous countries. There is evidence that health investments promote economic growth [1]. Infrastructural healthcare investments are therefore an authoritative pro-growth as well as a pro-equity instrument. Healthcare is a highly networked and systemic industry that affects projects, which need to be well-positioned in the territory, as shown by the Covid-19 pandemic [2] and synergic with other infrastructural facilities.

Public authorities are eager to find innovative solutions to foster sustainable welfare and increasingly seek private partners through public-private partnership (PPP) schemes [3] whose attractiveness remains disputed [4-8]. Healthcare Project Finance (PF) represents the financing of long-term infrastructure with a sophisticated financial structure where project equity and debt are used to finance the project, rather than to reward project sponsors [9].

Although the public proponent remains the key player, deciding strategies and managing healthcare core activities, the private actor performs the Project-Build-Operate-Transfer (PBOT) functions, within the period of the concession (typically, approximately 3 years of project and build, pursued by some 20-25 years of private management of non-core 
activities, ending up in a free transfer to the public). The main stakeholders are the private and public actors, linked by a contractual agreement (PPP). Other crucial stakeholders are represented by the banks that sponsor the private initiative (using a PF pattern), the pass-through sub-suppliers, and, last by not least, the patients that mostly interact with the public player. Each stakeholder will be considered to be a "node" connected to other stakeholders through "edges", consistently with network theory analysis representing an innovative way of interpreting corporate governance interactions.

The market mechanism that presides over the PPP auction (where private players compete to win the bid) is fully consistent with an intensive regulated industry such as healthcare and is witnessed by the many empirical cases of new public hospitals built and run with PPP/PF agreements [3-10].

Pressure for improving quality standards goes along with smart healthcare investments that are increasingly patient-centric [10], and risky [11], therefore threatening bankability. Bankability concerns the level of willingness of prospective lenders to finance the project, i.e., what amount and under what conditions, and is a crucial prerequisite for all the stakeholders involved in the infrastructural project-no money from the banks, no new hospital.

Following this framework, the research question of this study is focused on the savings deriving from the introduction of networked digital platforms in the PF/PPP mechanism, and on their consequent (positive) impact on bankability that stands out as a primary feasibility concern (no money, no party). These savings produce a "value pie" that can be partitioned among the contributing stakeholders.

Traditional stakeholders (shareholders, managers, employees, suppliers, financial lenders, customers, etc.) are complemented in the healthcare infrastructural industry by patients, public procurers, and private suppliers, coalescing around a Special Purpose Vehicle (SPV) that acts as a bridging/hub node. Pivoting digital platforms represent a further "virtual" stakeholder [12].

This study is, to the author's best knowledge, innovative, and it might describe both the specific healthcare sector, looking for patient-centered satisfaction and sustainability, and the traditional stakeholder relationships, re-engineered around digital platforms.

The research is organized as follows: after these introductory notes, there is a literature review in Section 2. The methodology is then exposed before an empirical simulation of how a typical healthcare PF investment may change when digital platforms are introduced. Impact on bankability is examined. A discussion and conclusion critically examine and summarize the main findings.

\section{Literature Review}

This study examines some applications to the specific healthcare industry of network governance patterns [13]. As the topic is highly interdisciplinary, this literature review illustrates the main streams consistent with each field, to discover how they may interact, and which are some tentative research gaps. The main subdivisions are:

1. healthcare PPP/PF investments;

2. network theory, digital platforms, and applications to healthcare (to make infrastructural investments "smart").

PPP research, starting from its meaning [14], covers different topics across multiple disciplines and is disseminated in many journals [15], also concerning the public administration discipline [16]. PPP policies are examined in [17]. A global survey of PPP experiences, inspiring PPP guidelines [18] is reported in $[19,20]$. Healthcare PPP surveys are reported in [16,21-24].

The critical choice between Traditional Procurement (internalized within the public player) and outsourced PPP/PF is now a cornerstone of cost-benefit analyses concerning complex infrastructural investments. This trade-off is driven by Value for Money (VfM) considerations that aim to optimize uneasy choices [9]. Patients are a crucial albeit 
under-investigated stakeholder, positively affected by smart technologies applied to public healthcare, which represent a trendy innovation [10].

Network theory-to be linked to digital platforms acting as bridging nodes in the PPP ecosystem-is explained in [25] whereas network governance applications are examined in $[12,13]$. A literature review of digital platforms is contained in $[26,27]$ that analyse sharing economy platforms.

Specific healthcare applications are discussed in [28] that review existing literature on digital health innovation ecosystems. Healthcare platforms are in most cases public [29], as they support public services for citizens. Healthcare savings due to digitalization are growing $[30,31]$. The impact of healthcare digitalization on smart hospital PF is examined in [32]. Digital care is characterized by low cost, high tech, and high access. In general, digitization creates value [33]. Technology is, however, a double-edged sword and may increase costs in healthcare [34,35], although its routine application may allow for savings.

Although healthcare PPP stakeholdership models have already been investigated in the literature, their interaction through innovative digital platforms has been hardly considered. Ref. [36] show that platforms leverage networked technologies to facilitate economic exchange, transfer information, and connect people. Refs. [37-39] examine [digital] value co-creation networks that are consistent with a platform-driven PPP ecosystem.

These studies, however, are not specifically dedicated to the peculiar healthcare industry, nor they address innovative PPP issues where dyadic public-private interactions are extended to multi-lateral and digital networking.

A short analysis of the main applications of healthcare digital platforms, complementary to the literature review, is propaedeutic to a critical examination of the bankability issues. Table A1 (reported in the Appendix A) contains an illustration of some actions and strategies that may have a positive socio-economic impact on healthcare strategies, improving overall sustainability.

The interpretation of the healthcare PPP firm (the private SPV, and its relations with the external stakeholders, as the public part, the banks, the patients, etc.) in terms of a Coasian nexus of contracts can be generalized to a network of interrelations, following the paradigms of network theory and the still pioneering explanation of the interactions among PPP stakeholders [13]. Bankability is a crucial PF/PPP milestone (no money, no party, ... ) that can be reinterpreted with these networked digital patterns.

To the author's best knowledge, there are no comprehensive studies that analyze the research question of this paper, considering how traditional and innovative (digital) stakeholders interact in healthcare PPP investments, impacting the project's bankability. This study is therefore intended to fill a gap in the extant literature, targeting the healthcare industry that proves highly sensitive to digitalization, a core component of e-health, $\mathrm{m}$ health, or telemedicine.

\section{Methodology}

As anticipated in the introduction, the research question examines healthcare investments, considering the (positive) impact of digitalization on their financial and economic margins. The purpose is to show that:

1. Higher margins improve bankability, with a cascade benefit on all the involved stakeholders.

2. The value-adding "pie" sharing among the stakeholders may be conveniently mastered by the networking digital platforms, igniting a value co-creation process.

The value-generating process can be exemplified in Figure 1 that shows the consequential networked steps along the value chain and its recursive return to the value-originating platform (from 4 to 1 ). In particular, it will be demonstrated that:

1. Digitalization-driven cost savings positively impact financial and economic marginality (proxied by the Earnings Before Interests, Taxes, Depreciation and AmortizationEBITDA and other parameters) of the PPP/PF initiative, improving the networking interaction of the stakeholders. 
2. Better financial marginality improves the bankability of the project, making its acceptance likelier.

3. The additional value "pie" created by digitalization is subdivided among the main stakeholders (public; private; patients, etc.).

4. The interaction among the stakeholders is eased by the digital platform bridging properties, fostering the incentive to co-create and then share the additional value.

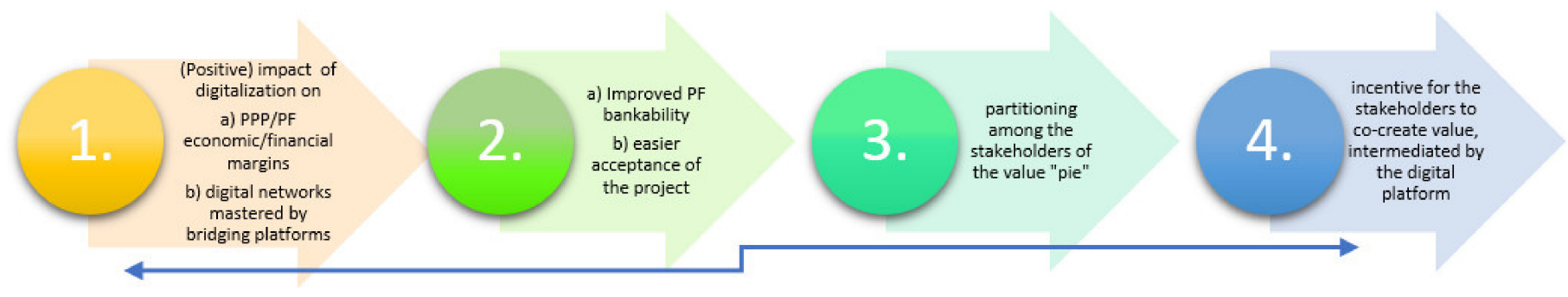

Figure 1. Value-generating Process Ignited by Digital Platforms.

Figure 1, with its double-sided arrow, shows that value co-creation is a circular process since the involved stakeholders (the public investor; the private SPV and their suppliers; the banks that sponsor the SPV, the patients, etc.) have an incentive to foster digitalization to monetize its proceeds.

A sensitivity simulation is based on a "traditional" (platform-free) business plan inspired by a generalization of four healthcare PPP/PF investments in Veneto (a NorthEastern region in Italy):

- $\quad$ New Hospital Center for Acutes-Monselice-Este (Padua) (2011) [40].

- Borgo Trento and Borgo Roma-Verona-Integrated University Hospital (2013) [41].

- $\quad$ Cittadella della Salute-Treviso Hospital (2017) [42,43].

- New hospital complex of Thiene and Schio (Vicenza) (2012) [44].

This case, readapted from [45], represents the basic template for a simulation of the impact of digital platforms. Within the forecast income statement, platforms increase operating revenues and decrease, thanks to managerial savings, the operating expenditure (OpEx). Their combined effect fosters operating leverage (the translation of higher revenues on operating profits that grow more than proportionally) and improves the EBITDA, expressed by subtracting monetary OpEx to operating revenues. A higher EBITDA has an immediate positive effect on liquidity generation, debt service capacity, and therefore bankability.

The analysis will start from the compared "without-with" examination of a straightforward network with that of a "smart" platform-driven network where new nodes are introduced. This methodology is consistent with the "with or without" differential approach traditionally used to estimate intangibles (e.g., comparing a firm with or without a patent), as illustrated in the International Valuation Standard 210 (par. 80.1).

The methodology is based on an empirical case, inspired by a sample of traditional healthcare PF investments, where digital savings are introduced with a sensitivity analysis, impacting economic margins, and eventually affecting the overall bankability of the project. Two complementary methodologies will be used in the next sub-paragraphs:

(a) An economic-financial sensitivity analysis, where digital savings impact on key PF parameters, including bankability;

(b) A mathematical interpretation, based on network theory, where the stakeholders of two ecosystems-respectively, without and with a digital platform-are compared.

This interdisciplinary methodology is consistent with the research question, as it allows a comprehensive description of the impact of digital savings, and can be applied to other PPP investments, even beyond the healthcare industry. Network theory gives an innovative reinterpretation of the interactions among the main PPP stakeholders. 


\subsection{From Standard to Smart Healthcare PF: A Sensitivity Simulation}

An empirical analysis of the impact of digitalization of healthcare long-term investments, such as those concerning new hospitals built and managed with PPP/PF agreements, is still missing, due to the novelty of the topic. The simulation will therefore be conducted starting from a generalized case of four Veneto-based hospitals realized with PF/PPP agreements (recalled in Section 3), analyzing the potential repercussion of digitalization on the revenues and costs of the private entity (SPV).

This empirical setting is consistent with the research question, as it provides a theoretical story of the main accounting and financial indicators that preside over the bankability issues, and the interrelations among the stakeholders. The sensitivity analysis, with the impact of digitalization, shows the potential effect of digital savings on the life-long parameters of the investment, consistently with the "without or with (digitalization) approach" indicated in the methods and illustrated in the comparison between Figures 2 and 3.

The income statement of the SPV is the "engine" behind any bankability consideration since it is within this accounting prospect that perspective economic margins are forecast, leading to liquidity creation and consequent debt service (the key concept behind any bankability issue).

The hypothetical impact on operating revenues and costs is the following:

1. a scenario with $+20 \%$ revenues $/-20 \%$ costs;

2. a scenario with $+15 \%$ revenues $/-15 \%$ costs;

3. a scenario with $+10 \%$ revenues $/-10 \%$ costs;

4. a scenario with $+5 \%$ revenues $/-5 \%$ costs;

5. a scenario with $+2 \%$ revenues $/-2 \%$ costs.

This sensitivity impact is estimated considering the potential repercussion on revenues and operating costs of healthcare-related digital platforms, as shown in Table A1 in the Appendix A. Any increase in the revenues or decrease in the operating costs (OpEx) driven by digitalization, improves financial and economic marginality, with a positive impact on bankability and value creation.

Economic margin improvements are likely to be substantial and self-fulfilling. This may for instance happen when bundling intangible applications within the platform (e.g., collecting healthcare big data from the Internet of Things (IoT) or other sensors, storing them in the cloud using interoperable databases, validating sensitive health data with blockchains, and then proceeding to their interpretation with artificial intelligence algorithms).

Although this variability in revenues and costs that inspires the sensitivity analysis is not backed by still unavailable empirical evidence, it seems reasonable since the combined use of bundled intangibles may bring to over 10\% variations both in (higher) revenues and (lower) costs. This variability is consistent with [46] according to which the potential benefits of using big data in analyzing operations management and supply chain activities bring to a $15-20 \%$ increase in Return on Investment (ROI), productivity, and competitiveness. A McKinsey study [47] shows that big data may reduce US healthcare costs by about $8 \%$. This indicates the importance of data mining and predictive analytics for more informed decision-making in supply chain management and operations [48,49].

The hypothesis that indicates a (meaningful) cost reduction is also consistent with the targets of an optimal healthcare standard cost policy, where purchase prices are intermediated and benchmarked using B2B digital platforms. A comparison among different hospitals, coordinated at the Regional level, shows the difference between each local spending policy and the optimal benchmark inspired by a shared sample. Standard healthcare costing is the foundation for controlling operational performance.

A brief comparison is illustrated in Table 1. Applying a sensitivity analysis to the base case, $2 \%, 5 \%, 10 \%, 15 \%$, and $20 \%$ growth in operating revenues (and a corresponding reduction in operating costs, mostly monetary OpEx) are reported in each column. 
Table 1. Impact of Digitalization on the Project Finance main parameters.

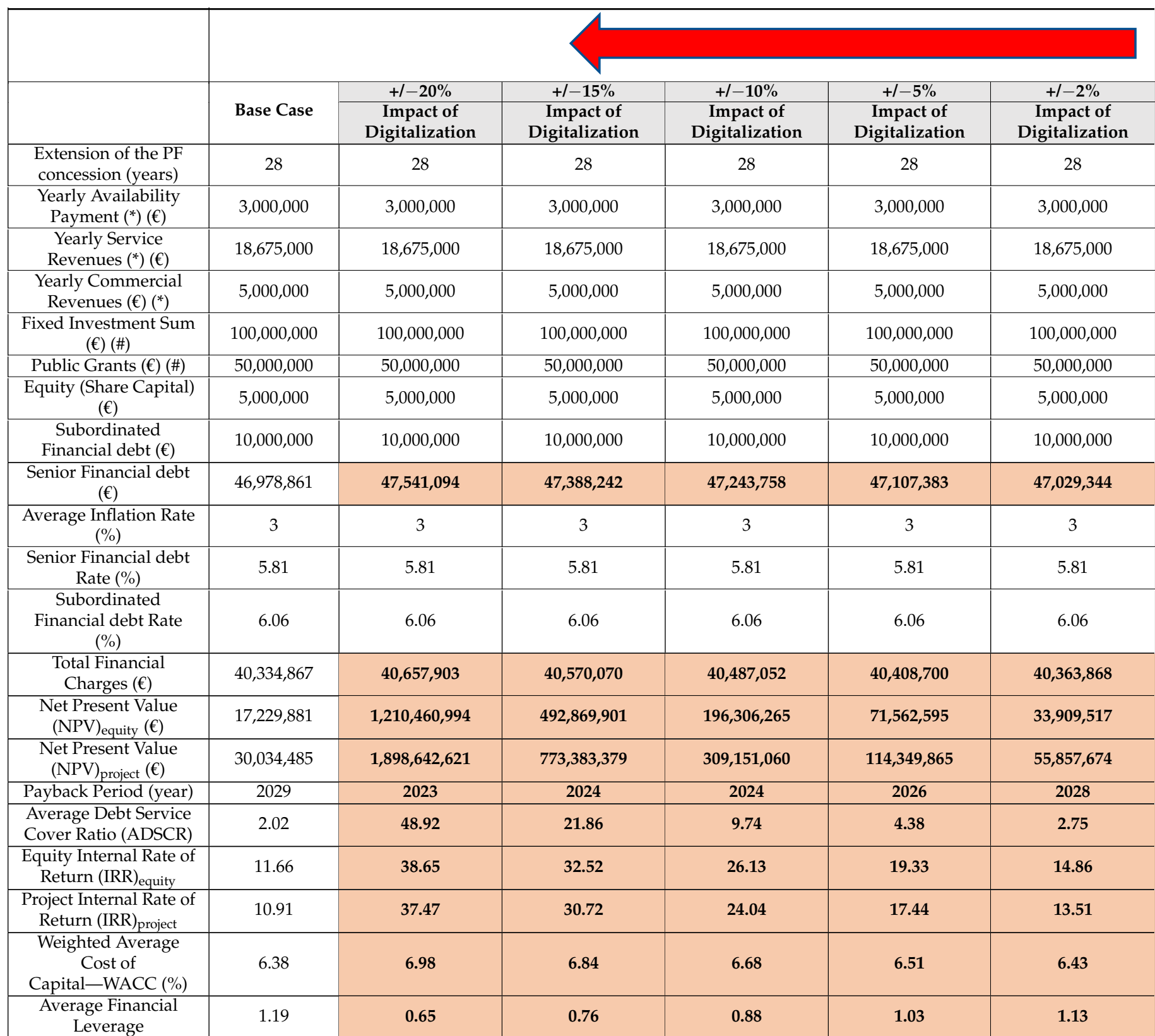

$\left.{ }^{*}\right)$ not including Value Added Tax, base 2019 (\#) including Value Added Tax.

The first data column illustrates the base case of a standardized healthcare PF of 3 years (considering the project and construction phase) +25 years of operations, where main input data refer to: the revenues of the SPV (availability payment from the public procurer + hot/cold revenues) yearly; the investment amount, backed by the equity and the debt; the crucial financial/macroeconomic variables (interest rates, inflation, etc.) that are not affected by digitalization.

Consistently with the described outline, the empirical case will be interpreted with:

(a) Financial and economic performance analysis.

(b) Network theory. 


\subsection{Financial and Economic Performance Analysis}

The (positive) impact on the overall PF healthcare performance, including bankability, is evident from the sensitivity analysis of the main indicators, as a response to the improvements in the economic marginality due to digital platforms:

(a) the Net Present Value (NPV) of the project substantially increases, and so does the Internal Rate of Return (IRR) of the project (both parameters incorporate financial debt service, being based on operating cash flows), showing respectively a greater amount of wealth creation, and a higher hurdle rate compared to a break-even WACC;

(b) even the residual remuneration of shareholders ( $\mathrm{NPV}_{\text {equity }}$ and IRR equity) consistently improves, indicating that after financial debt compensation is positive and substantial;

(c) the payback period shortens, witnessing a lower financial break-even;

(d) the average debt service coverage ratio substantially grows, showing an excess of operating cash flows created each year to properly serve the expiring financial debt (the threshold rate is 1); this is possibly the most important parameter for bankability, as it shows if and to which extent the SPV can generate enough liquidity to properly serve expiring financial debt;

(e) the financial leverage also decreases, showing a lower ratio of financial debt to equity;

(f) the WACC is the only parameter that (slightly) worsens, but this is just due to a weighting adjustment (improved economic/financial margins accelerate debt repayment, therefore diminishing the leverage and increasing the equity weights; since the cost of equity is higher than the cost of debt, the WACC increases).

In synthesis, the parameters are highly reactive to financial and economic improvements that affect the overall bankability of the project. Among the reasons for this remarkable sensitivity, we should first consider the long time of the project (28 years, in the example).

The digital-driven value increase of the "pie" is mainly witnessed by the cumulative Net Present Value (in coordination with the other parameters) that can be shared among the stakeholders represented in Figure 3:

- Even if the financial debtholders (mainly represented by the banks that preside over the bankability concerns) cannot increase the face value of their credit, they improve the likelihood of straightforward debt service that reduces delinquency risk.

- Sub-contractors follow a similar pattern, with no extra gains but a higher certainty of being fully paid in due time.

- Digital platforms are a pass-through virtual B2B2C stakeholder that may receive a fixed remuneration.

- Patients may hope for better care at more competitive prices.

The two remaining stakeholders that compete for the sharing of the "extra-pie" are represented by the backbone of the PPP agreement-the public concessionaire and the private SPV-respectively no. 1 and no. 4 of Figure 3 (displayed in Section 3.3). The incremental $\mathrm{NPV}_{\text {equity }}$ should accrue exclusively to the (private) shareholders of the SPV, whereas the incremental $\mathrm{NPV}_{\text {project }}$ should remunerate all the debtholders. As the remuneration of the banks and the pass-through suppliers is fixed, the bulk of these extra gains accrues to the SPV. Risk management by SPV stakeholders [50] remains a crucial issue that savings from digitalization may contribute to softening.

This simulation represents, however, a simplification of real life, ignoring competition among the private participants to the tender, and pressure for the public actor to compensate its real backing stakeholders-patients (that also coincide with ... voters). PPP/PF sources of finance are mainly concerned with bank loans. Other healthcare financial sources (universal healthcare coverage backed by public money; insurance program coverage, etc.) concern the public-patient relationship that is not affected by the PPP/PF architecture.

Excessive private rents foster auction competition among the private players, to the benefit of the public actor that reduces its burden, freeing resources that can be dedicated to better healthcare quality, higher outreach (further healthcare investments), or even 
lower taxation. The real ultimate beneficiary of digital-driven extra gains may therefore be represented by the public actor.

\subsection{Network Theory Interpretation}

Network theory is the analysis of graphs that illustrate (a)symmetric relations between discrete objects. In network science and computer science, network theory is included in graph theory: a network is routinely defined as a graph whose edges and/or nodes (vertices) have attributes (e.g., names).

A network is interdependent if it is represented by a system of coupled networks where nodes of one network depend on vertices in other networks. Networks represent a fundamental feature of complex ecosystems. Their interdependent structure could give an innovative interpretation of the interactions among different stakeholders.

Network theory is used in many disciplines, including biology, climatology, ecology, epidemiology, computer science, particle, or statistical physics, electrical engineering, economics, finance, operations research, and sociology. Network theory can be used in gene regulatory networks, metabolic networks, supply chain networks, the World Wide Web, and the Internet, social, or epistemological networks, etc. Beyond these traditional areas, network theory can ease the analysis of complex corporate governance structures [13], where composite stakeholders interact. This is the case in PPP/PF investments, such as those examined in this study.

The empirical setting may be understood as a theoretical story of healthcare networks, providing a complementary explanation of the research question.

Figures 2 and 3 back the "without-with" comparison, showing-with a simplified ecosystem's wiring diagram-a standard healthcare PPP network, and, respectively, a digital network mastered by a platform.

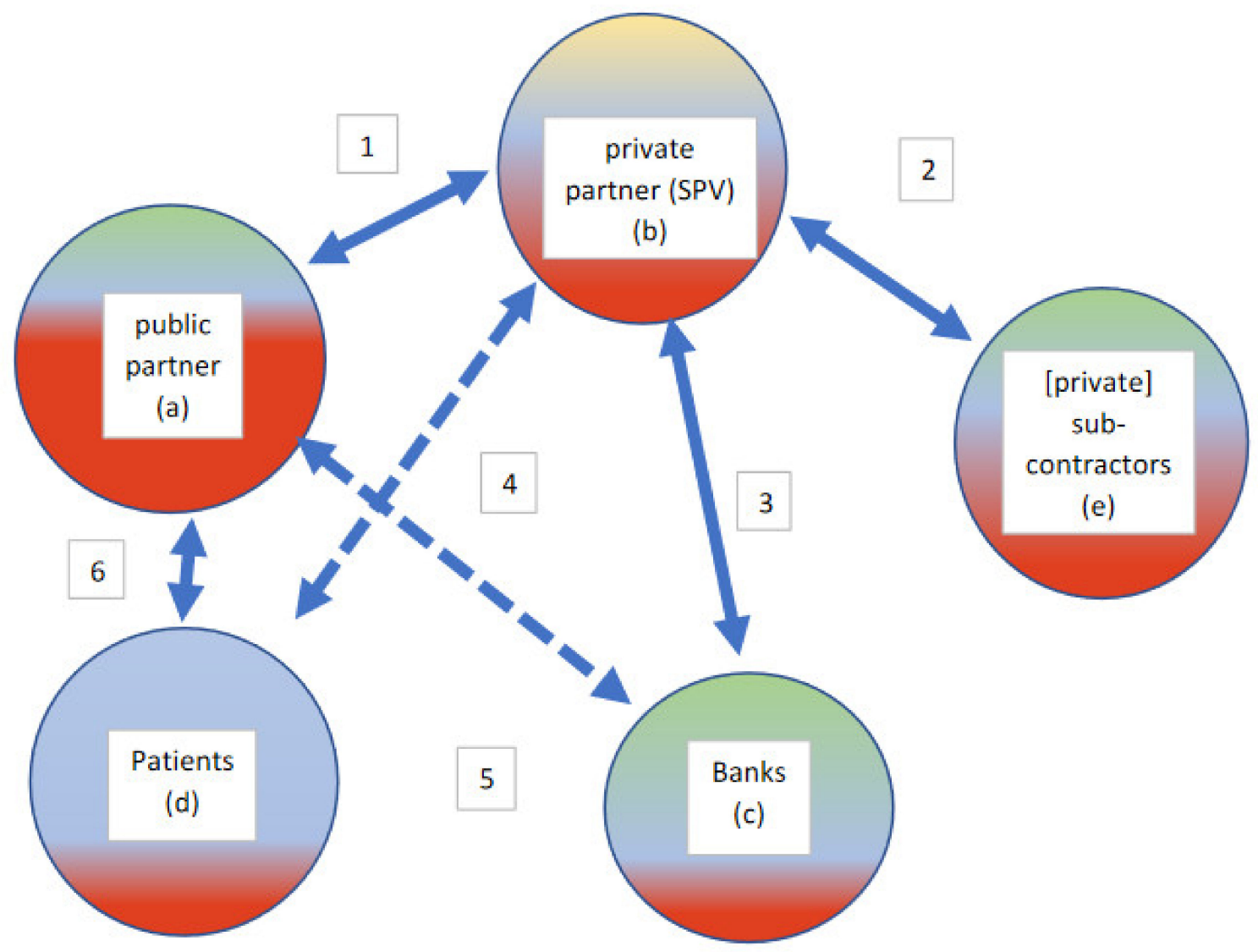

Figure 2. Standard Healthcare PPP Network during the Management Phase. 


\section{Legenda}

1. Private to Public invoicing: private income (cash-inflow) and specular public costs (cash-outflows)

2. Sub-contractors to Private invoicing: private costs (cash-outflows) and sub-contractors income (cash-inflow)

3. Private to Bank negative interests (costs and cash-outflows) and specular bank to private positive income (revenues and cash-inflows); bank to private financing and payback

4. Private supply to patients of non-core healthcare services

5. Treasury intermediation (public to private payments are mediated by the banking agent)

6. Public to the patient supply of services and patient to public payment of tickets

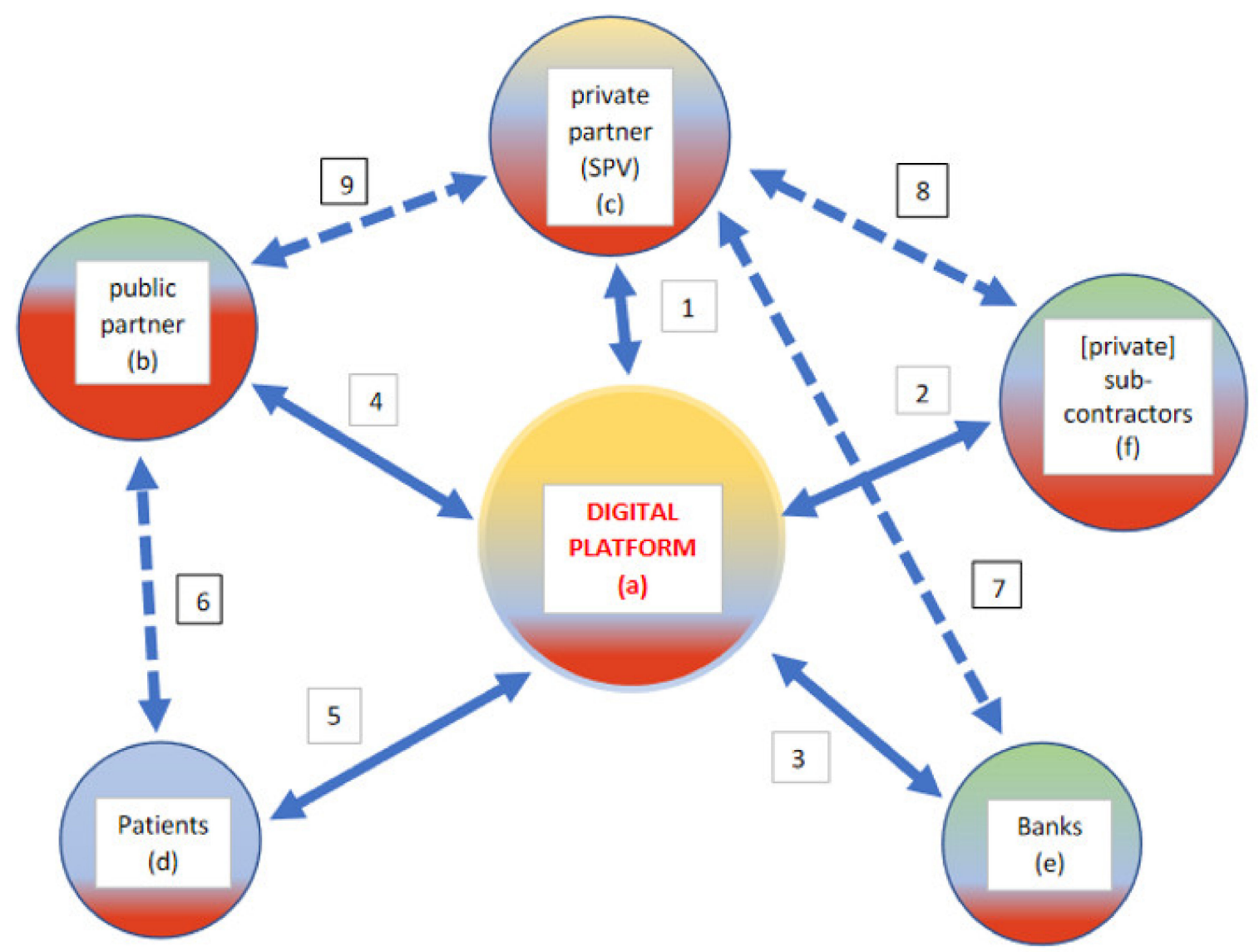

Figure 3. Digital Platform Intermediating a Healthcare PPP Network during the Management Phase.

Legenda

1 + 4. Private to Public invoicing Through the Digital Platform: private income (cash-inflow) and specular public costs (cash-outflows)

$2+1$. Sub-contractors to Private invoicing through the Digital Platform: private costs (cash-outflows) and sub-contractors income (cash-inflow);

digital B2B auctions are conducted through the platform, with time and cost savings along the digitized supply chain

$3+1$. Private to Bank negative interests (costs and cash-outflows) and specular bank to private positive income (revenues and cash-inflows)

through the Digital Platform; bank to private financing and payback

$1+5$. Private supply to patients (and visitors) of non-core healthcare services

$4+5$. Public to the patient supply of services and patient to public payment of tickets through the Digital Platform

5. Digital benefits for patients may be detected with Cost-Benefit Analysis and Cost-Effectiveness Analysis [51].

6. Direct contact between patients and hospital (for healthcare treatment, etc.).

7. Indirect relationship between the private actor and the sponsoring banks (not intermediated through the digital platform/mobile banking).

8. Supply of physical goods and services to the private SPV.

9. Contractual public-to-private agreements. Supply of physical goods and services.

The compared analysis of Figures 2 and 3 shows that in the latter the digital platform acts as an intermediating (bridging) hub, increasing the number of nodes (vertices) - and so the overall value and consistency of the network-but especially the quantity and quality of the links. For instance, any interaction between two agents mediated through the platform is digitally recorded in real-time and may fuel big data gathering and artificial intelligence elaboration.

The added value embedded in Figure 3 (compared to Figure 2) can be interpreted with network theory analysis [25], with a mathematical measurement of the degree of the nodes 
(number of links with other nodes), and a consequent estimate of their economic value. New connecting nodes with a system's centrality convey both information and economic transactions, partially reflecting the value increases of the PF parameters, as shown in Table 1.

The real finite network exemplified in Figure 3 (or even 2) is a complex system, bearing vulnerability due to interconnectivity (any "blackout" concerning the digital platform may bring severe problems for the whole ecosystem). The links of Figure 3 (numbered from 1 to 9) are bi-directional, therefore increasing the potential flow of data and transactions. A first sight comparison of Figures 2 and 3 shows that the latter graph, mastered by the digital platform (acting as a hub or central node) has more nodes and more (intense) connections that might be measured from the PF parameters.

In network (graph) theory, relations among nodes are formulated with an adjacency matrix - a square matrix used to show a finite graph as in Figure 2 or Figure 3. The parameters of the matrix show whether pairs of nodes are adjacent or not in the graphical representation. In this case, the adjacency matrix is a symmetric and $(0,1)$-matrix. Since each node is not linked to itself, there are zeros on its diagonal.

The degree of each node represents the number of links with other nodes and is mathematically expressed with a symmetric adjacency matrix that is the following (Table 2) for Figure 2 (with 5 nodes):

Table 2. Adjacency matrix of a Standard $5 \times 5$ PPP Network.

\begin{tabular}{|c|c|c|c|c|c|}
\hline & $\mathbf{a}$ & $\mathbf{b}$ & $\mathbf{c}$ & $\mathbf{d}$ & $\mathbf{e}$ \\
\hline $\mathbf{a}$ & 0 & 1 & 1 & 1 & 0 \\
\hline $\mathbf{b}$ & 1 & 0 & 1 & 1 & 1 \\
\hline $\mathbf{c}$ & 1 & 1 & 0 & 0 & 0 \\
\hline $\mathbf{d}$ & 1 & 1 & 0 & 0 & 0 \\
\hline $\mathbf{e}$ & 0 & 1 & 0 & 0 & 0 \\
\hline
\end{tabular}

However, the symmetric adjacency matrix for Figure 3 (6 nodes) is reported in Table 3:

Table 3. Adjacency matrix of a Digitized $6 \times 6$ PPP Network.

\begin{tabular}{|c|c|c|c|c|c|c|}
\hline & $\mathbf{a}$ & $\mathbf{b}$ & $\mathbf{c}$ & $\mathbf{d}$ & $\mathbf{e}$ & $\mathbf{f}$ \\
\hline $\mathbf{a}$ & 0 & 1 & 1 & 1 & 1 & 1 \\
\hline $\mathbf{b}$ & 1 & 0 & 1 & 1 & 0 & 0 \\
\hline $\mathbf{c}$ & 1 & 1 & 0 & 0 & 1 & 1 \\
\hline $\mathbf{d}$ & 1 & 1 & 0 & 0 & 0 & 0 \\
\hline $\mathbf{e}$ & 1 & 0 & 1 & 0 & 0 & 0 \\
\hline $\mathbf{f}$ & 1 & 0 & 1 & 0 & 0 & 0 \\
\hline
\end{tabular}

The value of each network can be estimated with Metcalfe's law that shows that the effect of a network is proportional to the square of the number of connected users (nodes) of the system $\left(n^{2}\right)$. Therefore, network Figure $2_{2}=25$, and network Figure $3=36$ (considering, for simplicity, that both networks have the same weights that measure the value of each link. This could underrate the effective value of the links of the platform).

The digital platform, potentially operating always (24/7) and everywhere, reduces paths and distances, through its intermediating function that minimizes the number of links among the other nodes (shortest path). It also increases the network connectedness, creating additional paths between otherwise disconnected nodes (for instance, banks and sub-contractors that are connected through the platform in Figure 3 but are not connected in Figure 2).

It is therefore basically shown even in mathematical terms that the digitally mastered network outperforms the original (simple) network. The impact on bankability, although not directly calculated, is deemed to be positive. This also derives from the network robustness, fostered by the digital plasticity of resilient platforms. 
A further extension of the network interpretation of Figures 2 and 3 may be represented by multilayer networks [52] that are connected thanks to the presence of bridging digital platforms, as shown in Figure 4.

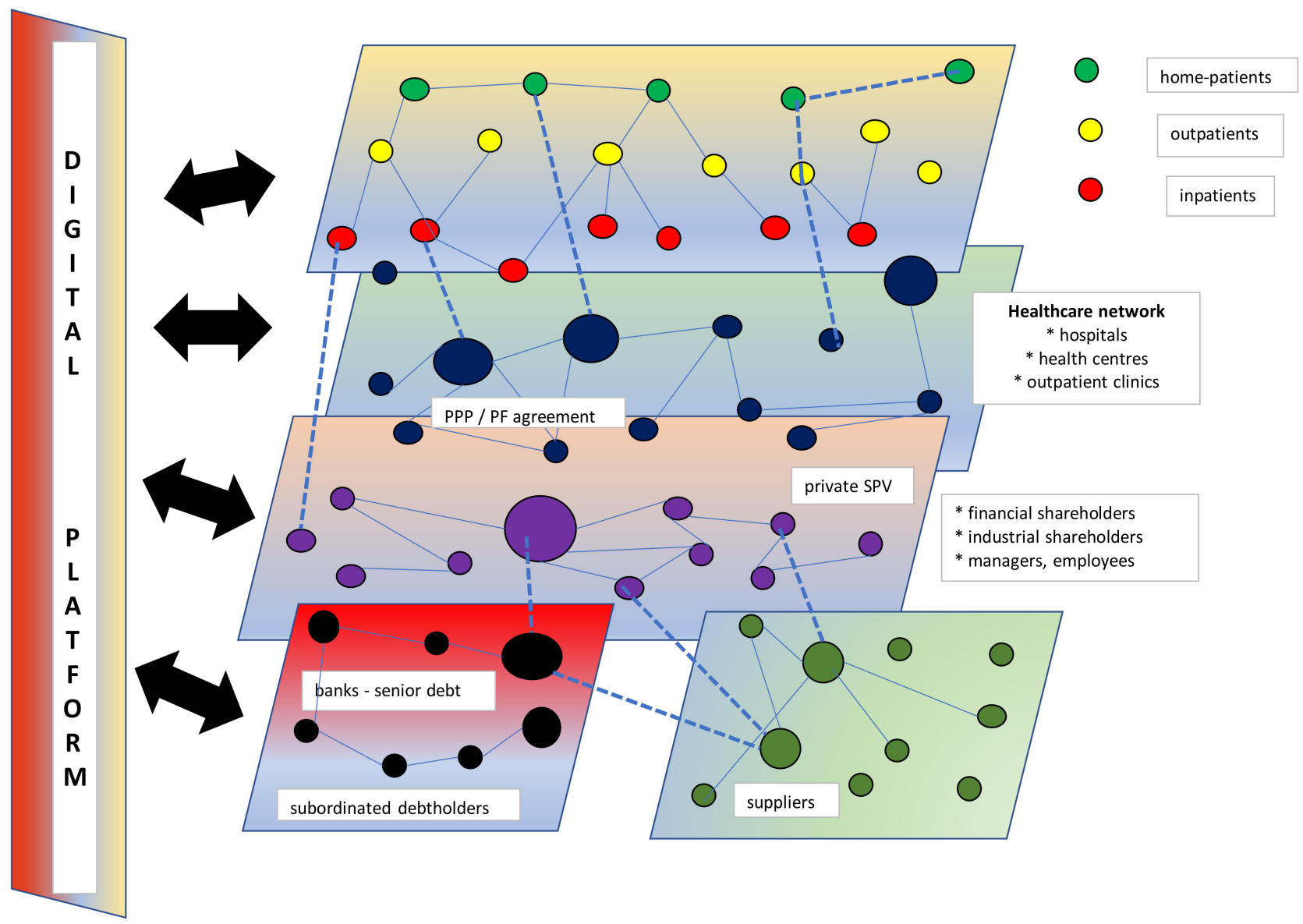

Figure 4. Multilayer PPP networks with a bridging digital platform.

Figure 4 illustrates the centripetal impact of the digital platform on the layers that get closer and superimposed in some areas, sharing some common node, and intensifying intra-layer and inter-layer edges. Multilayer networking increases the overall value of the PPP ecosystem and may inspire frontier interdisciplinary research.

\section{Discussion}

The empirical simulation has shown that long-termed PF investments are extremely sensitive to any change in their economic marginality. The income statement is the real "engine" behind the project, mainly because the production of the internal liquidity starts from the EBITDA-a financial and economic margin.

The model proposed in this study can be applied to different healthcare systems that may provide or not universal healthcare coverage. This occurs since the relationship between the public and the private player, which represents the core part of the PPP governance network, is not affected by the socio-economic model that links patients to the public supplier of healthcare services. The way patient costs are covered (by universal healthcare coverage, private insurance companies, or other mixed remuneration patterns) does not affect the public-private relationship since patients only interact with the public part that runs the hospital. Only ancillary services (Information Communication Technology, canteen, laundry, shops, parking, etc.) are run by the private player, within the boundaries of the contractual agreements. 
Highly leveraged investments such as healthcare PF base their capacity to properly serve debt on EBITDA-driven self-financing. Although the private players, through their SPV, bear most of the entrepreneurial risk, benefits are increasingly shared with the public actor and the patients, thanks again to the presence of digital platforms that favor information sharing and value co-creation patterns [37,39].

The empirical simulation confirms that improved financial and economic marginality (driven by digital gains) boosts bankability parameters (mainly represented by the debt service coverage ratio or the NPV or the leverage). Even if the SPV is a startup, it follows a cash-flow pattern (consistent with the PF business plan and the PPP contractual agreements) that is different from that of typically unbankable newborn businesses. Criticalities change across time, especially when they concern long-term investments, divided into two interdependent phases (project and construction, followed by management). Bankability concerns weaken across time since leverage decreases, and debt service is fueled by internally generated liquidity (EBITDA).

Although bankability is formally an issue only for the private part (no money, no party), capital rationing criticalities may impede the participation of ailing competitors, eventually also damaging the public proponent. Bankability, however, mostly remains a private sustainability concern.

It should be noted, as a caveat, that both Figures 2 and 3 represent, both economically and mathematically, a static picture of the PPP framework. A dynamic representation may consider first the two distinct phases (construction and operation/management of the hospital), and then the evolution of the financial and economic parameters (it is, for instance, well-known that bankability concerns peak at the end of the construction period when leverage is maximized and the private SPV has not yet started invoicing for the management of the hospital). This represents a hint for future research on the topic. Figure 3 represents the operational phase since during the construction patients are not present and suppliers are different.

Evolving networks experiment degree dynamics, consistent with each node's temporal evolution. This does not reflect in the framework represented in Figure 3, where all the stakeholders remain unchanged, but the intensity of their relations is modified (the bank, for instance, becomes less strategic when its repayment schedule consolidates).

Some further considerations involve the role of digital platforms and, more generally, of technology. These risky investments are mostly undertaken, in a PPP/PF investment package, by the private actor, due also to his expertise. The rewards concern both economic savings and better care; while the former mostly accrue to the private player (and may be partially shared with the public concessionaire), the latter typically benefit the patients. Patients and the public player should command a priority because the healthcare system is evolving towards patient-centered governance [10] backed by a public actor whose budget constraints can be softened mainly by savings. Private rewards for the SPV and its sub-contractors should be mitigated by competition and linked to pay-for-performance patterns, incentivizing technological upgrades [11].

Lessons from the covid-19 pandemic also show the importance of aseptic digital stakeholders, such as platforms that ease real-time information sharing. E-health and $\mathrm{m}$-health applications, pivoting around digital platforms, also favor smart working and social distancing, contributing to transform, whenever possible, non-acute in-patients into out-patients or home-patients [53]. These socio-economic considerations, and their sustainability impact, favor telemedicine applications that ease (whenever possible, always excluding emergency treatment or surgical needs) hospital decongestion and avoid unnecessary traveling. Time-cost savings and quality of life improvements ultimately accrue to the patient, a traditionally neglected stakeholder.

\section{Conclusions}

This study analyses the impact of digital savings mastered by networking platforms on PPP/PF bankability. Given the multi-faceted financial and institutional pressures for 
healthcare systems, this type of setting could have important contributions to the research and practice of healthcare trends, consistently with the Sustainable Development Goal 3 (Ensure healthy lives and promote well-being for all at all ages), and with Environmental, Social \& Governance-ESG targets.

The paper shows that digital platforms exemplify a bridging node that reshapes the networked interaction of connected PPP stakeholders.

In its industry application, the research concentrates on healthcare investments that concern an essential social infrastructure characterized by increasing sustainability issues, mainly because of public budgetary pressures, and the aging population. The main result is that digitalization creates savings and improves Value for Money (a price/quality ratio), softening bankability concerns. Its impact on socio-economic sustainability can be shared among the stakeholders, first represented by the patients and the public actors. Should the private players try to accumulate excessive rents, taking advantage of the technological savings, they would face increased competition, eased by digital comparability that reduces information asymmetries. PPP/PF competition is regulated in the contractual bid (and then agreement with the private winner) that incorporates the sophisticated regulation prescriptions of the healthcare industry. The feasibility study that precedes the PPP auction incorporates the public political-economic factors that are typically complex to settle (everybody longs for a new hospital close to home; growing budget constraints are to be considered, etc.).

There are manyfold practical implications of this study.

First, it is shown that digitalization adds value, with a positive impact on financial and economic marginality, therefore improving bankability. This is magnified both by the long-term schedule of PPP investments, and by the still undetected likelihood that innovation (concerning the synergistic interaction of big data, cloud computing, artificial intelligence, and blockchains) could boost productivity in a data- and technology-sensitive industry as healthcare.

Secondly, value co-creation can reward all the stakeholders, improving the Value for Money but also the healthcare performance [54-56] in a sector where quality can make the difference between survival and death. The benefit extracted from the sharing of the value "pie" (with Results-Based Financing, Pay-for-Performance, or other rewarding agreements) represents an incentive for all the stakeholders to nurture a self-fulfilling value co-creation process, consistent with the representation of Figure 1.

As anticipated, due to the novelty of the topic and the current lack of track-record documentation of smart (platform-driven) healthcare investments, a real case is currently not available. This represents a limitation of the study that may be overcome whenever evidence becomes available or with appropriate forecasting modeling of current cases upgraded with technological applications.

Disruptive technological advances will also contribute to reshaping the digital supply and value chain, shortening its passages, and producing transactional savings. New research streams may be inspired by oncoming evidence of the digital impact on business modeling and value creation of innovative PPP patterns. Digital platforms may contribute to reshaping the life cycle of healthcare PPP projects, improving their resilience, and softening the risk concerns that endanger bankability and long-term economic sustainability.

The findings of this study may be extended to industries outside healthcare [57] or generalized to other stakeholder connections $[58,59]$ bridged by digital platforms and interpreted with network theory principles. The role of bridging platforms has hardly been investigated in a PPP framework, but it gives an innovative interpretation of the dynamic relationships between technology-driven stakeholders. The proposed approach reshapes traditional corporate governance models, reinterpreting the theory of the firm (here represented by the private SPV) in a wider ecosystem, where digitalization eases transactions and data diffusion, to the benefit of all the involved stakeholders.

Funding: This research received no external funding. 
Institutional Review Board Statement: Not applicable.

Informed Consent Statement: Not applicable.

Data Availability Statement: Not applicable.

Conflicts of Interest: The author declares no conflict of interest.

\section{Appendix A}

Data deposition: Moro-Visconti, Roberto (2021), "Impact of healthcare digital platforms", Mendeley Data, V1, doi: 10.17632/zxdp38mv42.1.

Table A1. Impact of healthcare digital platforms.

\begin{tabular}{|c|c|}
\hline Action/Strategy/Device & Features and Impact \\
\hline 1. Inclusion of digital platforms in the healthcare supply chain & $\begin{array}{l}\text { Digital platforms enable and improve communication, } \\
\text { knowledge generation, and information diffusion. Digital } \\
\text { platforms accessed by a cluster of firms improve cooperation, } \\
\text { coordination, and collaboration [60]. Platforms add up in the } \\
\text { network a bridging node whose centrality improves traffic } \\
\text { (volume of transactions, data, etc.). }\end{array}$ \\
\hline 2. Digital scalability & $\begin{array}{l}\text { Innovative business models can achieve exponentially } \\
\text { increasing returns to scale as a response to digital disruption, } \\
\text { fostering the growth multiplier. Economies of scale and } \\
\text { experience lower the break-even point and foster long-term } \\
\text { sustainability and resilience of the healthcare supply chain, } \\
\text { even thanks to m-health applications [61]. }\end{array}$ \\
\hline $\begin{array}{l}\text { 3. Electronic health records (remote access and use to fuel big } \\
\text { data and decision-making) }\end{array}$ & $\begin{array}{l}\text { More and more health data are pulled from electronic health } \\
\text { records to inform clinician decision-making. Paperless records } \\
\text { are cheaper to store and use ubiquitously [62]. }\end{array}$ \\
\hline $\begin{array}{l}\text { 4. Inclusion of MedTech, digital health, and other innovative } \\
\text { suppliers }\end{array}$ & $\begin{array}{l}\text { Digital health's primary value is to improve the triple aim: } \\
\text { better outcomes, greater access, and affordable care (lower } \\
\text { costs). Digital health has the power to decrease costs by } 50 \% \text { or } \\
\text { more [63]. MedTech is a double-edged sword, with great } \\
\text { potential but risky outcomes. MedTech can be effective in } \\
\text { cutting healthcare costs, reduce repetitive tasks, and foster } \\
\text { treatment optimization plans. }\end{array}$ \\
\hline 5. Price-based competition with B auctions & $\begin{array}{l}\text { Online reverse auctions (with one buyer and many competing } \\
\text { sellers) are reshaping healthcare. E-auctions reduce transaction } \\
\text { costs, ease coordination among stakeholders. Quality } \\
\text { assessment may represent an obstacle to comparative auctions, } \\
\text { and therefore standardization, whenever possible, is needed. }\end{array}$ \\
\hline 6. Healthcare analytics & $\begin{array}{l}\text { Acquisition and interpretation of (big) data improve the patient } \\
\text { experience, decrease readmission rates, and provide a better } \\
\text { quality of care, bringing to quality improvements, health cost } \\
\text { reduction, and increased patient satisfaction. }\end{array}$ \\
\hline 7. M-apps for access and feedbacks & $\begin{array}{l}\text { Providers adopt m-health using mobile apps to ease clinical } \\
\text { communication with patients to improve the management of } \\
\text { hospital workflows. Mobile apps allow effective optimization } \\
\text { of communication between providers, patients, and their } \\
\text { caregivers, with a } 24 / 7 \text { personalized management of a patient's } \\
\text { condition. Bottom-up patient feedback (possibly, in real-time) } \\
\text { refocus top-down strategies, fueling big data creation. }\end{array}$ \\
\hline
\end{tabular}


Table A1. Cont.

8. Disease management/surveillance

9. Transformation of (non-acute) in-patients to out-patients and home-patients

10. Transmission of secured information through Blockchains/patient-driven interoperability

11. Personalized/precision medicine

12. Feedbacks from patients (customer experience/patient portals) Evaluation of treatment effectiveness-assessment of patient's acuity level

13. Digital medical devices

14. Telemedicine, e-health, m-health

15. Artificial intelligence applications-(Early) prediction of pathologies-digital epidemiology

16. Result-Based Financing (RBF) (Pay-for-Performance)
Epidemic is a complex problem that can be traced using network theory [64]. Disease surveillance increasingly requires m-health devices and strategies. Prompt identification of patient zero represents, whenever possible, a mighty target. Chronic patients (suffering from diabetes, cardiovascular diseases, etc.) may avoid, whenever possible, unnecessary hospitalization, improving $\mathrm{m}$-health and remote monitoring [53]. Savings and other socio-economic benefits are potentially enormous.

Patient-centered interoperability requires new challenges concerning privacy and security, incentives, technology, and governance that represented a prerequisite for scalability. Blockchain technology might facilitate the exchange of secured data through digital access rules, data aggregation, patient identity, and data immutability [65].

Precision/personalized medicine differentiates people into different groups. Practices, interventions, medical decisions, and/or products are tailored to the individual patient according to their predicted response or risk of disease. Personalized medicine can tailor the fittest therapy with the highest safety margin for better patient care.

Patients' feedbacks may derive from data collected through M-apps (see point 7), fostering data mining applications [66]. Feedbacks enhance value co-creation, reducing information asymmetries and feeding big data. Electronic documentation can be used to predict patient acuity [67].

Digital medicine started around 2007 with the introduction of smartphones. Mobile devices connected with the Internet were incorporated in technology platforms following telemedicine patterns. Wearable sensors, endowing hand-held devices with the ability to acquire images and perform lab assays, complement the framework. This has resulted in a new path for generating in real-time, and in a real-world environment, medical data by the individual [68].

Telemedicine applications are increasingly important in healthcare. Indispensable tools for remote patient monitoring, home healthcare, and disease management are made available. Applications are fully consistent with networking digital platforms (see Figures 2 and 3). E-health and m-health may improve health outcomes (diagnosis, treatment, reduced hospitalization, longer life expectancy ... )

Prediction of pathologies can be carried forward with artificial intelligence patterns. Healthcare data and big data analytics are increasingly available, making the successful applications of AI in healthcare possible. Powerful AI techniques, driven by relevant clinical questions, can unlock clinically relevant information hidden in the massive amount of data, assisting clinical decision-making [69]. (Early) prediction of pathologies is enhanced by a combination of MedTech, precision medicine, patient-centered feedbacks, $m$-health, etc.

RBF for health consists of a non-monetary transfer or cash payment made to a manager, provider, or consumer as an incentive to use or deliver priority healthcare services. Payment is subordinated to measurable actions and benchmark savings. Technological applications in a PPP context can produce public savings that may be partially used to remunerate private players for their non-routine efforts [11]. 


\section{References}

1. Yang, Y.; Zheng, R.; Zhao, L. Population aging, health investment and economic growth: Based on a cross-country panel data analysis. Int. J. Environ. Res. Public Health 2021, 18, 1801. [CrossRef] [PubMed]

2. Baxter, D.; Casady, C.B. Proactive and strategic healthcare public-private partnerships (PPPs) in the coronavirus (Covid-19) epoch Sustainability 2020, 12, 5097. [CrossRef]

3. Hueskes, M.; Verhoest, K.; Block, T. Governing public-private partnerships for sustainability: An analysis of procurement and governance practices of PPP infrastructure projects. Int. J. Proj. Manag. 2017, 35, 1184-1195. [CrossRef]

4. Barlow, J.; Roehrich, J.; Wright, S. Europe sees mixed results from public-private partnerships for building and managing health care facilities and services. Health Aff. 2013, 32, 146-154. [CrossRef] [PubMed]

5. Boyer, E.J.; Van Slyke, D.M.; Rogers, J.D. An empirical examination of public involvement in public-private partnerships: Qualifying the benefits of public involvement in PPPs. J. Pub. Adm. Res. Theor. 2016, 26, 45-61. [CrossRef]

6. Hellowell, M. The price of certainty: Benefits and costs of public-private partnerships for healthcare infrastructure and related services. Health Serv. Manag. Res. 2016, 29. [CrossRef]

7. Kosycarz, E.A.; Nowakowska, B.A.; Mikołajczyk, M.M. Evaluating opportunities for successful public-private partnership in the healthcare sector in Poland. J. Pub. Health 2019, 27, 1-9. [CrossRef]

8. Pereira, M.A.; Ferreira, D.C.; Marques, R.C. A critical look at the Portuguese public-private partnerships in healthcare. Int. J. Health Plan. Manag. 2020, 36, 302-315. [CrossRef]

9. Moro Visconti, R. Multidimensional principal-agent value for money in healthcare project financing. Public Money Manag. 2014, 34, 259-264. [CrossRef]

10. Moro Visconti, R.; Martiniello, L. Smart Hospitals and Patient-Centered Governance. Corp. Ownersh. Control. 2019, 16, 83-96. [CrossRef]

11. Moro Visconti, R.; Martiniello, L.; Morea, D.; Gebennini, E. Can public-private partnerships foster investment sustainability in smart hospitals? Sustainability 2019, 11, 1704. [CrossRef]

12. Moro Visconti, R. Corporate governance, digital platforms, and network theory: Information and risk-return sharing of connected stakeholders. Manag. Control. 2020, 2, 179-204. [CrossRef]

13. Moro Visconti, R. Combining Network theory with corporate governance: Converging models for connected stakeholders. Corp. Ownersh. Control. 2019, 17, 125-139. [CrossRef]

14. Hodge, G.; Greve, C.; Biygautane, M. Do PPP's work? What and how have we been learning so far? Public Manag. Rev. 2018, 20, 1105-1121. [CrossRef]

15. Narbaev, T.; De Marco, A.; Orazalin, N. A multi-disciplinary meta-review of the public-private partnerships research. Constr. Manag. Econ. 2020, 38, 109-125. [CrossRef]

16. Wang, H.; Xiong, W.; Wu, G.; Zhu, D. Public-private partnership in Public Administration discipline: A literature review. Public Manag. Rev. 2018, 20, 293-316. [CrossRef]

17. Rosell, J.; Saz-Carranza, A. Determinants of public-private partnership policies. Public Manag. Rev. 2020, 22, 1171-1190. [CrossRef]

18. Aizawa, M.A. Scoping Study of PPP Guidelines. DESA Working Paper No. 154. January. Available online: https://www.un.org/ esa/desa/papers/2018/wp154_2018.pdf (accessed on 26 April 2021).

19. Akintoye, A.; Beck, M.; Kumaraswamy, M. Public Private Partnerships; A Global Review; Routledge: London, UK, 2016.

20. Moro Visconti, R.; Dos, A.; Pelin Gurgun, A. Public-private partnerships for sustainable healthcare in emerging economies. In Handbook on Public-Private Partnerships in Developing E Emerging Economies; Leitão, J., Ed.; Emerald Group Publishing: London, UK, 2017; pp. 409-442.

21. Fanelli, S.; Salvatore, F.P.; De Pascale, G.; Faccilongo, N. Insights for the future of health system partnerships in low- and middle-income countries: A systematic literature review. BMC Health Serv. Res. 2020, 20. [CrossRef]

22. Roehrich, J.K.; Lewis, M.A.; George, G. Are public-private partnerships a healthy option? A systematic literature reviews. Soc. Sci. Med. 2014, 113, 110-119. [CrossRef]

23. Torchia, M.; Calabrò, A.; Morner, M. Public-Private Partnerships in the Health Care Sector: A systematic review of the literature. Public Manag. Rev. 2015, 17, 236-261. [CrossRef]

24. Venkat Raman, A.; Björkman, J.W. Public-private partnerships in healthcare. In The Palgrave International Handbook of Healthcare Policy and Governance; Palgrave Macmillan: London, UK, 2016; pp. 376-392.

25. Barabási, A. Network Science; Cambridge University Press: Cambridge, UK, 2016.

26. Asadullah, A.; Faik, I.; Kankanhalli, A. Digital Platforms: A Review and Future Directions; Twenty-Second Pacific Asia Conference on Information Systems, Japan. 2018. Available online: https://www.academia.edu/37873177/Digital_Platforms_A_Review_ and_Future_Directions (accessed on 26 April 2021).

27. Sutherland, W.; Jarrahi, M.H. The sharing economy and digital platforms: A review and research agenda. Int. J. Infor. Manag. 2018, 43, 328-341. [CrossRef]

28. Iyawa, G.E.; Herselman, M.; Botha, A. A Scoping Review of Digital Health Innovation Ecosystems in Developed and Developing Countries, Conference: IST Africa, At Windhoek, Namibia, 2017. Available online: https://www.researchgate.net/publication/31801331 2_A_Scoping_Review_of_Digital_Health_Innovation_Ecosystems_in_Developed_and_Developing_Countries (accessed on 26 April 2021). 
29. Ranerup, A.; Zinner Henriksen, H.; Hedman, J. An analysis of business models in public service platforms. Gov. Inform. Q. 2016, 33, 6-14. [CrossRef]

30. Menvielle, L.; Audrain-Pontevia, A.; Menvielle, W. The Digitization of Healthcare. New Challenges and Opportunities; Palgrave Macmillan: Cham, Switzerland, 2017.

31. Velez-Lapão, L. The Challenge of Digital transformation in Public Health in Europe? Eur. J. Public Health. 2019, 29. [CrossRef]

32. Moro Visconti, R.; Morea, D. Healthcare digitalization and pay-for-performance incentives in smart hospital project financing. Int. J. Environ. Res. Pub. Health 2020, 17, 2318. [CrossRef]

33. Kagermann, H. Change through digitization -value creation in the age of Industry 4.0. In Management of Permanent Change; Albach, H., Meffert, H., Pinkwart, A., Reichwald, R., Eds.; Springer Fachmedien: Wiesbaden, German, 2015.

34. EXPH (Expert Panel on Effective Ways of Investing in Health). Assessing the Impact of Digital Transformation of Health Services. 2019. Available online: https:/ / ec.europa.eu/health/sites/health/files/expert_panel/docs/022_digitaltransformation_en.pdf (accessed on 26 April 2021).

35. Nghiem, S.H.; Connelly, L.C. Convergence and determinants of health expenditures in OECD countries. Health Econ. Rev. 2017, 7, 1-11. [CrossRef]

36. Fenwick, M.; McCahery, J.A.; Vermeulen, E.P.M. The End of 'Corporate' Governance: Hello ‘Platform' Governance. Eur. Bus. Organ. Law Rev. 2019, 20, 171-199. [CrossRef]

37. Blaschke, M.; Uwe, R.; Kazem, H.; Aier, S. Design principles for digital value co-creation networks: A service-dominant logic perspective. Electron. Mark. 2019, 29, 443-447. [CrossRef]

38. Beirão, G.; Patrício, L.; Fisk, R.P. Value Co-creation in service ecosystems. J. Serv. Manag. 2017, 28, 227-249. [CrossRef]

39. Galvagno, M.; Dalli, D. Theory of value co-creation: A systematic literature review. Manag Serv Qual. 2014, 24, 643-683. [CrossRef]

40. Net Engineering. New Acute-Care Hospital Complex of Monselice-Este. 2015. Available online: https://www.net-italia.com/ wp-content/uploads/2015/05/Monselice-Este-Hospital.pdf (accessed on 26 April 2021).

41. Steam. Borgo Roma Hospital-Verona. 2020. Available online: https://www.steam.it/project/borgo-roma-hospital-verona/ (accessed on 26 April 2021).

42. Addarii, F.; Lipparini, F.; Medda, F. Impact Investing Innovation: Bringing Together Public, Private and Third Sectors to Create Greater Value: The Case of the Public Private Partnership Initiative for the New Public Hospital of Treviso. In Social Impact Investing Beyond the SIB Evidence from the Market; La Torre, M., Calderini, M., Eds.; Palgrave Macmillan: Cham, Stwitzerland, 2018; pp. 115-140.

43. Steam. New Cittadella Sanitaria of Ca' Foncello Hospital-Treviso. 2020. Available online: https://www.steam.it/project/newcittadella-sanitaria-of-ca-foncello-hospital-treviso/ (accessed on 26 April 2021).

44. Finlombarda. Finlombarda survey of Project Finance in Healthcare Sector; Maggioli Editore: Rimini, Italy, 2012.

45. Moro Visconti, R.; Morea, D. Big Data for the Sustainability of Healthcare Project Financing. Sustainability 2019, 11, 3748. [CrossRef]

46. Dubey, R.; Gunasekaran, A.; Childe, S.J.; Wamba, S.F.; Papadopoulos, T. The impact of big data on world-class sustainable manufacturing. Int. J. Adv. Manufact. Techn. 2016, 84, 631-645. [CrossRef]

47. McKinsey\&Company. Big Data: The Next Frontier for Innovation, Competition, and Productivity. 2011. Available online: https:/ / www.mckinsey.com/ \{\}/media/McKinsey/Business\%20Functions/McKinsey\%20Digital/Our\%20Insights/Big\% 20data\%20The\%20next\%20frontier\%20for\%20innovation/MGI_big_data_full_report.ashx (accessed on 26 April 2021).

48. Papadopoulos, T.; Gunasekaran, A.; Dubey, R.; Altay, N.; Childe, S.J.; Fosso-Wamba, S. The role of Big Data in explaining disaster resilience in supply chains for sustainability. J. Clean Prod. 2017, 142, 1108-1118. [CrossRef]

49. Witjas-Paalberends, E.R.; van Laarhoven, L.P.M.; van de Burgwal, L.H.M.; Feilzer, J.; de Swart, J.; Claassen, E.; Jansen, W.T.M. Challenges and best practices for big data-driven healthcare innovations conducted by profit-non-profit partnerships- $\mathrm{A}$ quantitative prioritization. Int. J. Health Manag. 2018, 11, 171-181. [CrossRef]

50. Burke, R.; Demirag, I. Risk management by SPV partners in toll road public private partnerships. Pub. Manag. Rev. 2019, 21, 711-731. [CrossRef]

51. Bergmo, T.S. How to measure costs and benefits of ehealth interventions: An overview of methods and frameworks. J. Med. Internet Res. 2015, 17, e254. [CrossRef]

52. Bianconi, G. Multilayer Networks; Oxford University Press: Oxford, UK, 2018.

53. Moro Visconti, R.; Larocca, A.; Marconi, M. Accessibility to First-Mile health services: A time-cost model for rural Uganda. Soc. Sci. Med. 2020, 265, 1-12. [CrossRef]

54. Cappellaro, G.; Ricci, A. PPPs in health and social services: A performance measurement perspective. Public Money Manag. 2017, 37, 417-424. [CrossRef]

55. Catuogno, S.; Arena, C.; Saggese, S.; Sarto, F. Performance implications of public-private partnerships in research hospitals: Lessons from the involvement of a charity. Health Serv. Manag. Res. 2016, 29, 91-98. [CrossRef]

56. De Marco, A.; Mangano, G. Risk and value in privately financed health care projects. J. Constr. Eng. Manag. 2013, 139, 918-926. [CrossRef]

57. Cui, C.; Liu, Y.; Hope, A.; Wang, J. Review of studies on the public-private partnerships (PPP) for infrastructure projects. Int. J. Proj. Manag. 2018, 36, 773-794. [CrossRef] 
58. Benítez-Ávila, C.; Hartmann, A.; Dewulf, G.; Henseler, J. Interplay of relational and contractual governance in public-private partnerships: The mediating role of relational norms, trust and partners' contribution. Int. J. Proj. Manag. 2018, 36, 429-444. [CrossRef]

59. Biygautane, M.; Neesham, C.; Al-Yahya, K. Institutional entrepreneurship, and infrastructure public-private partnership (PPP): Unpacking the role of social actors in implementing PPP projects. Int. J. Proj. Manag. 2019, 37, 192-219. [CrossRef]

60. Cremona, L.; Lin, T.; Ravarini, A. The Role of Digital Platforms in Inter-Firm Collaboration. In Proceedings of the 8th Mediterranean Conference on Information Systems, Verona, Italy, 3-5 September 2014.

61. Prasad, S. Designing for Scalability and Trustworthiness in mHealth Systems. In Proceedings of the 11th International Conference on Distributed Computing and Internet Technology, ICDCIT 2015, Bhubaneswar, India, 5-8 February 2015; Natarajan, R., Barua, G., Patra, M.R., Eds.; Springer: Cham, Switzerland, 2015.

62. Kruse, C.S.; Stein, A.; Thomas, H.; Kaur, H. The use of electronic health records to support population health: A systematic review of the literature. J. Med. Syst. 2018, 42, 214. [CrossRef]

63. Wasden, C.; Wasden, M. Tension: The Energy of Innovation. How Harnessing Tension Accelerates and Fuels Your Creative Genius; Scipio Press: Midway, UT, USA, 2015.

64. Han, S.; Preciado, V.; Nowzari, C.; Pappas, G. Data-driven network resource allocation for controlling spreading processes. IEEE Tran. Net. Sci. 2015, 2, 1-11. [CrossRef]

65. Gordon, W.J.; Catalini, C. Blockchain technology for healthcare: Facilitating the transition to patient-driven interoperability. Comput. Struct. Biotech. J. 2018, 16, 224-230. [CrossRef]

66. Koh, H.C.; Tan, G. Data mining applications in healthcare. J. Health Inf. Manag. 2011, 19, 64-72.

67. Kontio, E.; Airola, A.; Pahikkala, T.; Lundgren-Laine, H.; Junttila, K.; Korvenranta, H.; Salakoski, T.; Salanterä, S. Predicting patient acuity from electronic patient records. J. Biom. Inform. 2014, 51, 35-40. [CrossRef]

68. Topol, S. A decade of digital medicine innovation. Sci. Transl. Med. 2019, 11, eaaw7610. [CrossRef]

69. Jiang, F.; Jiang, Y.; Zhi, H.; Dong, Y.; Li, H.; Ma, S.; Wang, Y.; Dong, Q.; Shen, H.; Wang, Y. Artificial intelligence in healthcare: Past, present, and future. Stroke Vasc. Neurol. 2017, 2, 230-243. [CrossRef] 